\title{
Preparation and properties of multi-branched poly(D-lactide) derived from polyglycidol and its stereocomplex blends
}

\author{
A. Petchsuk ${ }^{1}$, S. Buchatip ${ }^{1}$,W. Supmak ${ }^{1}$, M. Opaprakasit ${ }^{2}$, P. Opaprakasit ${ }^{3 *}$ \\ ${ }^{1}$ National Metal and Materials Technology Center, Thailand Science Park, 12120 Pathum Thani, Thailand \\ ${ }^{2}$ Center of Excellence on Petrochemical and Materials Technology, Department of Materials Science, Faculty of Science, \\ Chulalongkorn University, 10330 Bangkok, Thailand \\ ${ }^{3}$ School of Bio-Chemical Engineering and Technology, Sirindhorn International Institute of Technology (SIIT), \\ Thammasat University, 12121 Pathum Thani, Thailand
}

Received 10 March 2014; accepted in revised form 2 June 2014

\begin{abstract}
Multi-branched poly(D-lactide)s (mbPDLAs) with various structures are synthesized via ring-opening polymerization by using polyglycidol (PG) macro-initiators. Their chemical structures and thermal properties are controlled by adjusting feed ratios of D-lactide (DLA) and PG. The materials are blended with commercial linear poly(L-lactide) ( $l$-PLLA) to form a stereocomplex structure. Effects of $m b$ PDLAs structures and $l$-PLLA $/ m b$ PDLA ratios on the blends' thermal, mechanical, and rheological properties are evaluated. Mechanical properties of the stereocomplex blends, especially elongation at break and toughness, are dependent on the blend compositions, in which a 90:10 ratio exhibits the most desirable properties. The material also exhibits the lowest complex viscosity, which provides easy processing conditions. This is achieved by the incorporation of copolymers with multi-branched structures and an ability to form a much stronger stereocomplex structure.
\end{abstract}

Keywords: polymer blends and alloys, polylactide, stereocomplex, multi-branched, polyglycidol

\section{Introduction}

Polylactide or polylactic acid (PLA) is a degradable polymer that is widely used in many applications, especially packaging, biomedical, agricultural, and environmental fields, due to its biodegradability, biocompatibility, and its renewable monomer resources. Despite these excellent characteristics, its thermal stability, durability, impact strength, and heat deformation temperature are significantly low, which limit its use in certain applications $[1,2]$. Various physical and chemical modifications have been employed to improve these properties, e.g. copolymerization with other monomers [3-11], or blending with other (co)polymers [5, 9, 10, 12-15].
Stereocomplexation is a promising technique to enhance PLA properties, by utilizing the strong interaction between its helical stereo-conformations, i.e., poly(L-lactide) (PLLA) and poly(D-lactide) (PDLA). This PLLA/PDLA stereocomplex exhibits a unique crystalline structure and morphology $[2,10,12,16]$, which has a melting temperature $\left(T_{\mathrm{m}}\right) 50^{\circ} \mathrm{C}$ higher than its homopolymer counterparts. The stereocomplex structure has high potential to improve heat resistivity and mechanical properties (tensile strength, Young's modulus, and elongation at break) of the materials [17]. The structure can be obtained by either solution or melt blending methods. Recently, supercritical fluids

\footnotetext{
${ }^{*}$ Corresponding author, e-mail: pakorn@siit.tu.ac.th

(C) BME-PT
} 
[18], microwave [19], and nano-processing techniques [20-22] have been employed in the stereocomplex formation. Preparation, structures, properties, and applications of this structure have been extensively studied [17, 23-27]. Formation of stereocomplex structure is usually accompanied by homo-crystallization, predominantly when high molecular weight PLAs are employed [2, 10]. A complete stereocomplexation, without homo-crystallite, is obtained from an equimolar mixture of sufficiently-low molecular weight PLLA and PDLA.

Stereocomplexation is also observed in block copolymers of L-lactide (LLA) and D-lactide (DLA) during polymerization, or during solid state polymerization of small-sized PLLA and PDLA [24, 28-30]. Stereoblock PLA copolymers have been used as compatibilizers in an enhancement of stereocomplexation efficiency, by suppressing the homo-crystallite formation of large-sized PLLA and PDLA [24]. However, these stereoblock copolymers cannot be processed into fibers or films, because of their relatively low molecular weight. Recently, a preparation of high-molecular weight stereoblock copolymers by employing non-equimolar LLA/DLA ratios was reported [31]. A complete stereocomplex without homo-crystallite was obtained when PDLA compositions of at least $15 \%$ was employed. An effective but rather expensive process of radiationinduced crosslinking was also employed to enhance the stereocomplex formation and to lower processing temperatures of its low molecular weight blends [32]. Although various structural formation mechanisms and analyses of PLA stereocomplex have been proposed, insights into the improvement of their toughness and rheological properties have not been presented.

Inclusion of branch-structured polymers into brittle plastics leads to improvement in their mechanical properties, especially toughness. Multi-branched polymers possess lower chain entanglements, lower solution and melt viscosity, but higher thermal stability, compared to their linear-structured counterparts. Other unique characteristics, i.e., their globular shape, and their large number of functional groups within a molecule, make these polymers suitable for various applications. The number and types of functional groups on these polymers can be modified to control their properties for specific applications [33]. Recently, multi-branched PLAs have been developed, and their possible applications have been assessed [34-38].

In this work, multi-branched poly(D-lactide)s ( $m b$ PDLAs), with different structures and properties, are prepared by employing polyglycidol (PG) as a macro-initiator. Depending on $m b$ PDLAs structures, the stereocomplex can be achieved by blending with linear poly(L-lactide) (l-PLLA). The major advantages of these stereocomplex mixtures derived from the branched constituents are an enhancement in the blend's mechanical properties and a decrease in melt viscosity. The resulting blends have high potential for use as high performance materials with easy fabrication processes.

\section{Experimental}

\subsection{Materials}

l-PLLA $\left(\bar{M}_{\mathrm{w}}=178000 \mathrm{~g} / \mathrm{mol}\right)$ and D-lactide monomer (DLA) were supplied by PURAC (Netherlands). Tin(II) octoate catalyst, $\mathrm{Sn}(\mathrm{Oct})_{2}$, was purchased from Wako (Japan). Glycidol was purchased from Aldrich (USA) and used as received. Ethyl acetate, chloroform, ethanol, and toluene solvents were purchased from Lab Scan (Thailand).

\subsection{Synthesis of $m b P D L A s$}

Polyglycidol (PG) is employed as a macro-initiator in the synthesis of $m b$ PDLAs. PG was prepared by a ring-opening polymerization of glycidol under an inert atmosphere, using $\mathrm{Sn}(\mathrm{Oct})_{2}$ catalyst at a polymerization temperature and time of $110^{\circ} \mathrm{C}$ and $3 \mathrm{~h}$. Effect of catalyst contents on structures of PG was examined by varying the contents from 0.25 $1.0 \mathrm{~mol} \%$. mbPDLAs were then synthesized via a ring-opening polymerization of DLA in a presence of $\mathrm{Sn}(\mathrm{Oct})_{2}$ catalyst and PG macro-initiator, under an inert atmosphere at $120^{\circ} \mathrm{C}$ for $24 \mathrm{~h}[39,40]$. The products were purified by dissolving in chloroform and precipitating in an ethanol/hexane mixture, and then dried under vacuum at $50^{\circ} \mathrm{C}$ for $24 \mathrm{~h}$. The DLA/PG molar ratios were varied from $5 / 1$ to $50 / 1$, to produce $m b$ PDLAs with different structures. The resulting copolymers were coded according to the feed DLA/PG ratios, e.g., $m b$ PDLA051 was synthesized from a $5 / 1$ ratio. 


\subsection{Stereocomplexation of $l$-PLLA and mbPDLAs}

Stereocomplex blends of $l$-PLLA $/ m b$ PDLA were prepared by mixing THF solutions of the constituents at various weight ratios, i.e., 90/10, 80/20, $70 / 30$ and 50/50. The mixtures were then casted on a glass surface, in which the solvent was removed by evaporation in a vacuum oven at room temperature for $48 \mathrm{~h}$. The resulting films were cut into rectangular shape with $50 \mathrm{~mm}$ gauge length and $15 \mathrm{~mm}$ width, according to ASTM D882, for mechanical tests.

\subsection{Characterizations}

Average molecular weights $\left(\bar{M}_{\mathrm{n}}, \bar{M}_{\mathrm{w}}\right)$ and polydispersity (PDI) of $m b$ PDLAs were measured using a Gel Permeation Chromatography (GPC), Waters e2695 with dual detectors: Viscotek Model 3580 Reflective Index detector and Model 270 differential viscometer detector comparative to mono-disperse polystyrene standards (4490-1 $112000 \mathrm{~g} / \mathrm{mol})$. The measurement was performed on PL gel 10 micron mixed B2 columns (Polymer Laboratories), at $35^{\circ} \mathrm{C}$, using tetrahydrofuran eluent with a flow rate of $1.0 \mathrm{~mL} / \mathrm{min}$. The glass transition $\left(T_{\mathrm{g}}\right)$ and melting $\left(T_{\mathrm{m}}\right)$ temperatures of the copolymers were determined by Differential Scanning Calorimeter (DSC) on a DSC822e Mettler Toledo. The samples were scanned twice from -60 to $250^{\circ} \mathrm{C}$ with a heating and cooling rate of $20.0^{\circ} \mathrm{C} / \mathrm{min}$. Chemical structures of $m b$ PDLAs were examined using an AVENCE ${ }^{\text {III }} 500 \mathrm{MHz}$ digital Nuclear Magnetic Resonance spectrometer (AV-500, Bruker Biospin; ), using $\mathrm{CDCl}_{3}$ (for $m b \mathrm{PDLAs}$ ) and $\mathrm{D}_{2} \mathrm{O}$ (for PG) solvents.

Tensile properties of blend samples were measured at room temperature on a universal testing machine (Instron model 55R4502, Instron Corp., USA) with a $100 \mathrm{~N}$ load cell and a crosshead speed of $50 \mathrm{~mm} / \mathrm{min}$, The specimens were prepared as rectangular specimens (prepared by solvent casting) with $50 \mathrm{~mm}$ gauge length and $15 \mathrm{~mm}$ width, according to ASTM D882. Each reported value is an average of measurements carried out on at least 4 specimens. Rheological properties, i.e., elastic modulus $\left(G^{\prime}\right)$, loss modulus $\left(G^{\prime \prime}\right)$, and complex viscosity $\left(\eta^{*}\right)$, were measured on a strain-controlled rheometer (ARES, TA Inc., New Castle, USA) with a torque transducer capable of measurement over the range of $2-200 \mathrm{~g} \cdot \mathrm{cm}$. Disc samples with a diameter of
$25 \mathrm{~mm}$ and $1 \mathrm{~mm}$ thickness were prepared by hotpressing. The strain amplitude for dynamic measurements was fixed at $5 \%$. The measurements were conducted in a temperature range of $190-250^{\circ} \mathrm{C}$, with a heating rate of $10^{\circ} \mathrm{C} / \mathrm{min}$ at a frequency of $1 \mathrm{rad} / \mathrm{s}$. Complex viscosity $\left(\eta^{*}\right)$ changes of the melts as a function of shear rate were conducted at a constant temperature of $230^{\circ} \mathrm{C}$.

\section{Results and discussion}

\subsection{Chemical structures and properties of mbPDLAs}

PG macro-initiators are synthesized by varying the catalyst contents from $0.25-1.0 \mathrm{wt} \%$. Figure $1 \mathrm{a}$ shows ${ }^{1} \mathrm{H}$ NMR spectrum of a PG sample, whose hydroxyl number is $340 \mathrm{mg} \mathrm{KOH} / \mathrm{g}$ sample (according to standard test method D4274-05, test method C). Complex signals, appeared in the range of 3.3$3.8 \mathrm{ppm}$, correspond to methylene and methine protons, while a resonance located at $4.7 \mathrm{ppm}$ is assigned to hydroxyl terminals. The integral ratio of methylene and methine/hydroxyl of $9 / 1$ is observed. Detailed information on chemical structure of PG can be derived from ${ }^{13} \mathrm{C}$ NMR Inverse Gated spectra, in which complicated patterns of perfect dentritic $(D)$, linear $(L)$, and terminal $(T)$ units can be identified. The assignments have been applied to

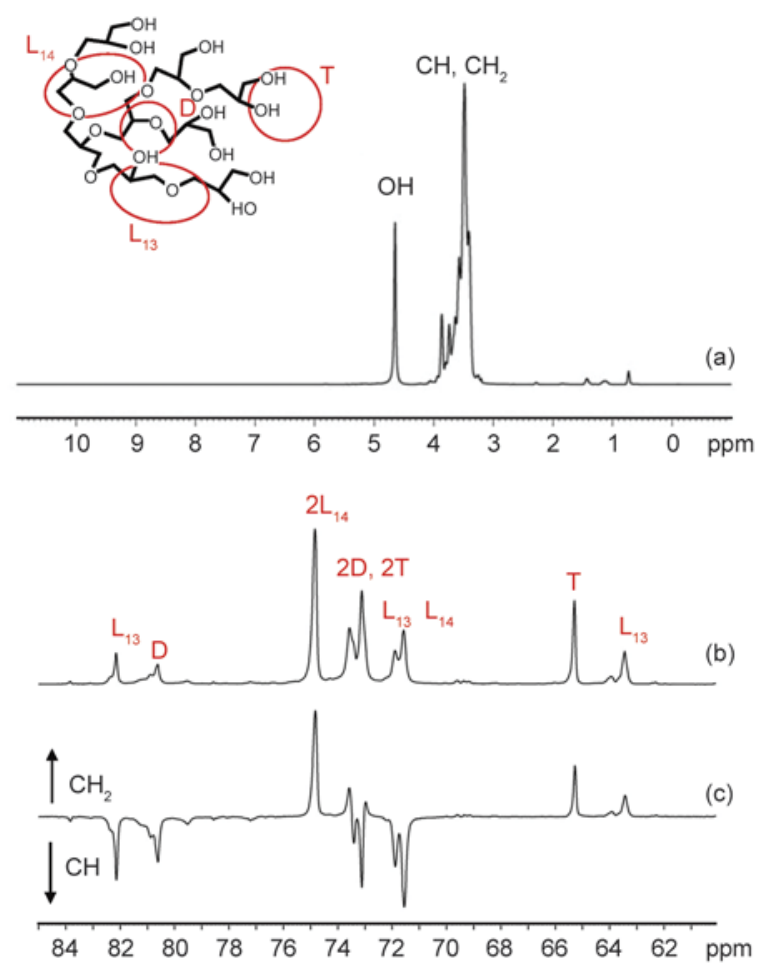

Figure 1. ${ }^{1} \mathrm{H}$ NMR (a), ${ }^{13} \mathrm{C}$ NMR (b), and ${ }^{13} \mathrm{C}$ NMR DEPT (c) spectra of $\mathrm{PG}$ synthesized from tin catalyst 
the spectra of PG synthesized from anionic polymerization [41-44]. Similar spectral characteristics are observed in this study, in which a tin catalyst is employed, as shown in a ${ }^{13} \mathrm{C}$ NMR and a distortionless enhancement by polarization transfer (DEPT) spectra in Figure $1 \mathrm{~b}$ and $1 \mathrm{c}$, respectively. This reflects a formation of similar products. The advantage of this synthesis route is, however, its one-step process, in which branching structures of PG products can be manipulated by varying the catalyst contents.

GPC chromatograms of PG synthesized from various catalyst contents are compared in Figure 2. At $1.0 \mathrm{~mol} \%$, a mono-modal size distribution is observed with a molecular weight at peak $\left(M_{\mathrm{p}}\right)$ of $2100 \mathrm{~g} / \mathrm{mol}$. As the catalyst content decreases to 0.5 and $0.25 \mathrm{~mol} \%$, the results show bi-modal distribution with similar $M_{\mathrm{p} 1}$ of $2000 \mathrm{~g} / \mathrm{mol}$, and a variation in $M_{\mathrm{p} 2}$ from 11500 to $24800 \mathrm{~g} / \mathrm{mol}$, respectively. The relative intensity of the high-molecular weight fraction increases with the decrease in the catalyst contents. Although the polydispersity value $(\sim 3.4)$ is significantly high, compared to that obtained from anionic polymerization [41-44], this synthesis route is considered as an alternative approach when structural perfection may not be a strict requirement for most applications.

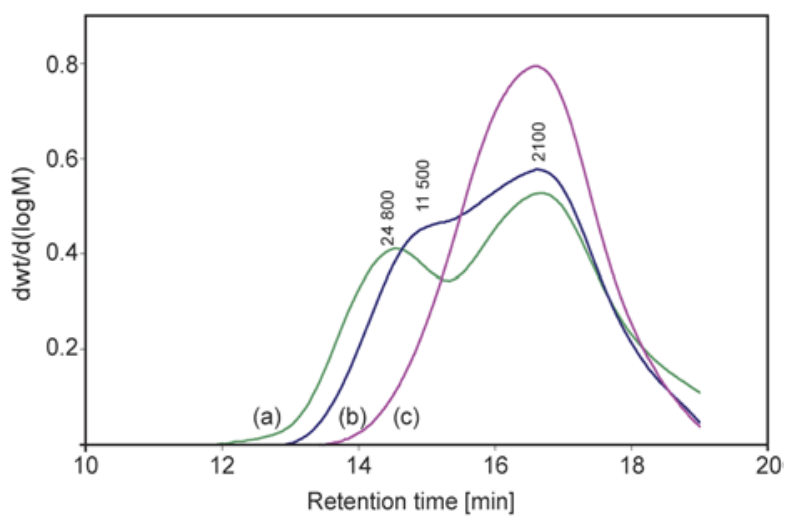

Figure 2. GPC chromatograms of PG synthesized at different catalyst contents: 0.25 (a), 0.5 (b), and $1.0 \mathrm{~mol} \%$ (c)
The relatively larger-sized PG prepared from a catalyst content of $0.25 \mathrm{~mol} \%$ is employed as a macroinitiator in the synthesis of $m b$ PDLAs. ${ }^{1} \mathrm{H}$ NMR spectra of the resulting copolymers obtained from various PG/DLA ratios are shown in Figure 3. Characteristic signals of $P G$ appear at 3.5-3.7 ppm $(\mathrm{d}, \mathrm{e})$, corresponding to methylene protons $\left(-\mathrm{CH}_{2}-\mathrm{CH}-\mathrm{O}\right)$ and methine proton $\left(-\mathrm{CH}_{2}-\mathrm{CH}-\mathrm{O}\right)$. The signal at 5.1-5.2 ppm (b) is assigned to methine $\left[\mathrm{O}=\mathrm{C}-\mathrm{CH}\left(\mathrm{CH}_{3}\right)_{-}-\mathrm{O}-\right]$ of lactate units. This confirms the presence of PDLA chains on the PG core. The integral ratios of the signals at 3.5-3.7 and 5.1-5.2 ppm reflect the PG/PDLA compositions in the copolymer chains. Average DLA length/ branch $\left(D_{1} A_{n}\right)$ is calculated from the integral ratio of ${ }^{\mathrm{b}} \mathrm{H} /{ }^{\mathrm{c}} \mathrm{H}$. Results on chain compositions and molecular weight of the copolymers are summarized in Table 1. Copolymers with $\bar{M}_{\mathrm{w}}$ ranging from 35000 $80000 \mathrm{~g} / \mathrm{mol}$ are obtained. The chain compositions are significantly similar to the corresponding feed ratios, reflecting a high incorporation efficiency of lactate units. DLA compositions and molecular weight of the copolymers increase with an increase of the DLA/PG feed contents. DLA $n$ value increases with an increase in the feed ratios from 5/1 to 20/1. Although $m b$ PDLA201 and $m b$ PDLA501 show

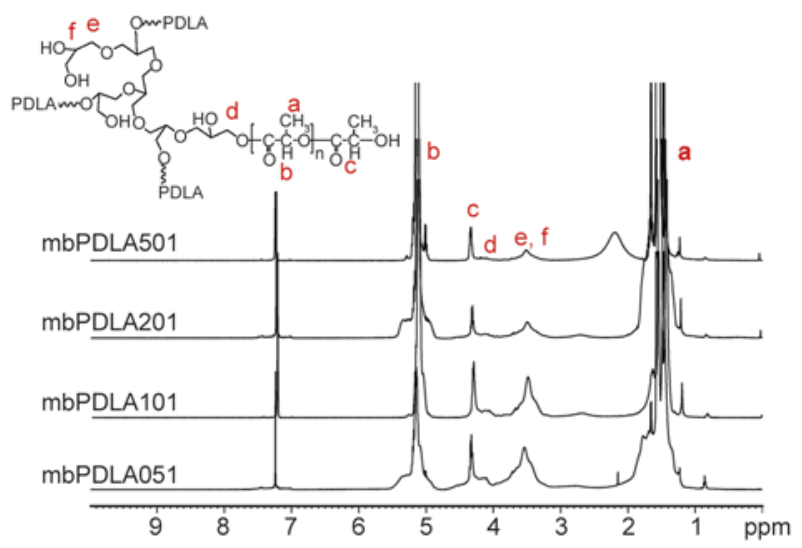

Figure 3. ${ }^{1} \mathrm{H}$ NMR spectra and signal assignments of $m b$ PDLAs

Table 1. Synthesis conditions and properties of $m b$ PDLAs

\begin{tabular}{|l|c|c|c|c|c|c|}
\hline \multirow{2}{*}{ Samples } & \multicolumn{2}{|c|}{ DLA/PG compositions } & \multirow{2}{*}{$\mathbf{D L A}_{\mathbf{n}}$} & \multirow{2}{*}{$\begin{array}{c}\overline{\mathbf{M}}_{\mathbf{n}}^{\mathbf{b}} \\
\text { [g/mol] }\end{array}$} & $\begin{array}{c}\overline{\mathbf{M}}_{\mathbf{w}}^{\mathbf{b}} \\
\text { [g/mol] }\end{array}$ & PDI \\
\cline { 2 - 3 } & in feed & in chain & & \\
\hline -PLLA & - & - & - & 88800 & 178100 & 2.01 \\
\hline$m b$ PDLA051 & $5 / 1$ & $83 / 17$ & 4 & 6700 & 35200 & 5.25 \\
\hline$m b$ PDLA101 & $10 / 1$ & $92 / 8$ & 7 & 20600 & 48900 & 2.37 \\
\hline$m b$ PDLA201 & $20 / 1$ & $96 / 4$ & 17 & 19100 & 64400 & 3.38 \\
\hline$m b$ PDLA501 & $50 / 1$ & $98 / 2$ & 17 & 23000 & 81500 & 3.54 \\
\hline
\end{tabular}

${ }^{a 1} \mathrm{H}$ NMR, ${ }^{\mathrm{b}} \mathrm{GPC}, \mathrm{DLA}_{\mathrm{n}}=$ average DLA length/branch, $\mathrm{PDI}=$ polydispersity index 
Table 2. Thermal properties of $m b$ PDLAs derived from DSC thermograms

\begin{tabular}{|l|c|c|c|c|c|c|}
\hline \multirow{2}{*}{ Samples } & \multicolumn{3}{|c|}{$\mathbf{1}^{\text {st }} \mathbf{s c a n}$} & \multicolumn{3}{|c|}{$\mathbf{2}^{\text {nd }} \mathbf{s c a n}$} \\
\cline { 2 - 7 } & $\begin{array}{c}\mathbf{T}_{\mathbf{g}} \\
{\left[{ }^{\circ} \mathbf{C}\right]}\end{array}$ & $\begin{array}{c}\mathbf{T}_{\mathbf{m}} \\
{\left[{ }^{\circ} \mathbf{C}\right]}\end{array}$ & $\begin{array}{c}\Delta \mathbf{H}_{\mathbf{m}} \\
{[\mathbf{J} / \mathbf{g}]}\end{array}$ & $\begin{array}{c}\mathbf{T}_{\mathbf{g}} \\
{\left[{ }^{\circ} \mathbf{C}\right]}\end{array}$ & $\begin{array}{c}\mathbf{T}_{\mathbf{m}} \\
{\left[{ }^{\circ} \mathbf{C}\right]}\end{array}$ & $\begin{array}{c}\Delta \mathbf{H}_{\mathbf{m}} \\
{[\mathbf{J} / \mathbf{g}]}\end{array}$ \\
\hline$l$-PLLA & - & 179 & 44.7 & 58 & 174 & 45.4 \\
\hline$m b$ PDLA051 & 18 & - & - & 29 & - & - \\
\hline$m b$ PDLA101 & 36 & 90 & 11.9 & 37 & - & - \\
\hline$m b$ PDLA201 & 50 & 125 & 32.5 & 49 & - & - \\
\hline$m b$ PDLA501 & 46 & 140 & 36.2 & 44 & 135 & 14.1 \\
\hline
\end{tabular}

similar DLAn values, a difference in their average molecular weights reflects different numbers of lactate branches per molecule. This, in turn, imposes strong effect on physical and mechanical properties of the copolymers, discussed later.

DSC thermograms of $m b$ PDLAs are compared with $l$-PLLA in Figure 4. Their thermal properties derived from $1^{\text {st }}$ heating scans are summarized in Table 2. $l$ PLLA exhibits cold crystallization in both of its $1^{\text {st }}$ and $2^{\text {nd }}$ heating scans, indicating that its crystallization is not complete at the applied DSC cooling rate, due to its long-chain structure. From the $1^{\text {st }}$ heating cycles, all $m b$ PDLAs exhibit melting characteristics
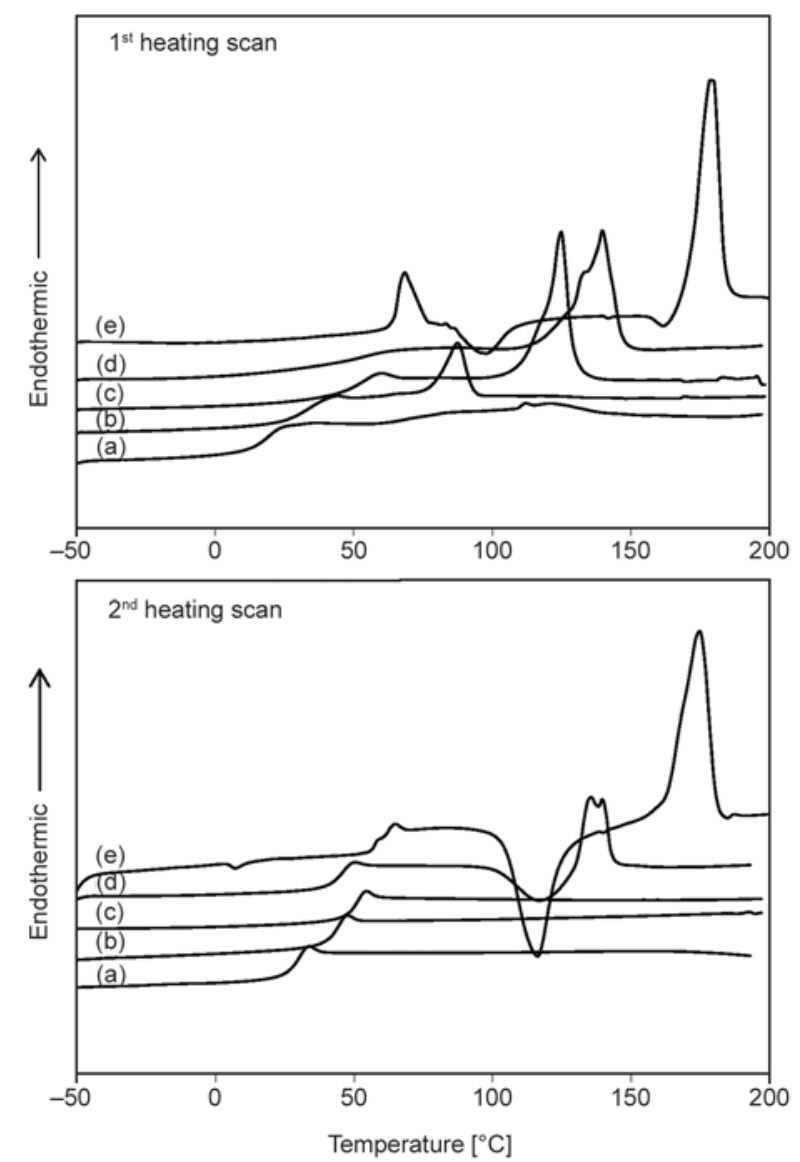

Figure 4. DSC thermograms of $m b$ PDLAs synthesized at various DLA/PG molar ratios: (a) 5/1, (b) 10/1, (c) 20/1, (d) 50/1, and (e) $l$-PLLA without cold crystallization. This is likely because these samples are prepared from a solvent-casting technique, which allows high freedom of crystallization. $T_{\mathrm{m}}$ 's of $m b$ PDLAs shift toward higher temperatures, whose heat of fusion values $\left(\Delta H_{\mathrm{m}}\right)$ also increases, with an increase in DLA block lengths and DLA contents of the chains. This indicates a strong influence of DLA sequences on crystalline structure of the copolymers.

In the $2^{\text {nd }}$ heating scans, however, cold crystallization and melting characteristics of $m b$ PDLAs are not observed, except $m b$ PDLA501. This reflects the influences of the samples structures and their thermal history, in which the multi-branched structure retards crystallizability of molten $m b$ PDLAs during DSC cooling and re-heating cycles. For the largest copolymer in the series ( $m b$ PDLA501), however, its sufficiently-long DLA sequences enable formation of crystalline domains upon re-heating. The results from both heating scans show that the copolymers have lower $T_{\mathrm{g}}$ than $l$-PLLA, due to their shorter DLA sequences. The $T_{\mathrm{g}}$ values increase with the copolymer's molecular weights.

\subsection{Thermal properties of $l$-PLLA/mbPDLA stereocomplex blends}

Effects of $m b$ PDLA structures and the blend compositions on properties of $l$-PLLA $/ \mathrm{mbPDLA}$ stereocomplex are investigated. Figure 5 shows DSC thermograms ( $2^{\text {nd }}$ heating scan) of blends (prepared at a 90/10 ratio) consisting of various mbPDLAs. This non-equimolar blend composition is employed to investigate interplay between crystallization behaviors of homo-crystallite and stereocomplex. Ther-

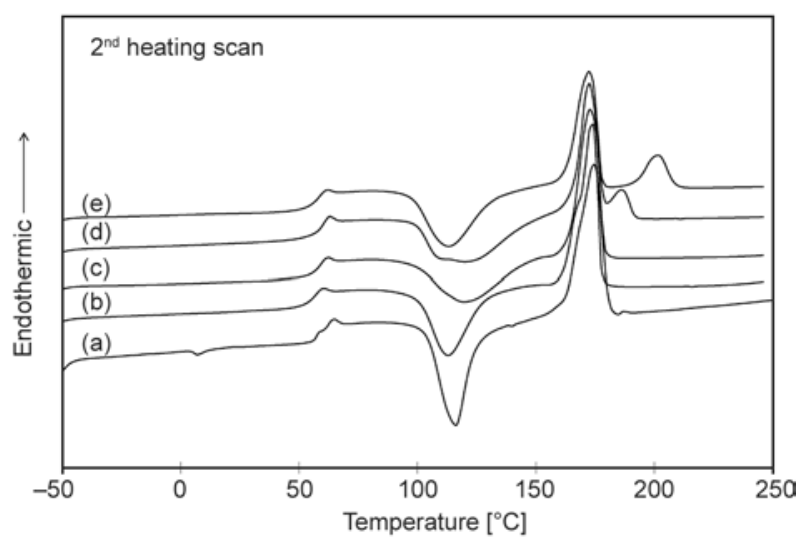

Figure 5. DSC thermograms of (a) $l$-PLLA and $l$-PLLA/ $m b$ PDLA501 stereocomplex blends (prepared at a 90/10 blend ratio) containing: (b) mbPDLA051, $\begin{array}{lll}\text { (c) } m b P D L A 101, & \text { (d) } m b \text { PDLA201, and }\end{array}$ (e) $m b$ PDLA501 
Table 3. Thermal properties ( $2^{\text {nd }}$ heating scan) of $l$-PLLA and $l$-PLLA $/ m b$ PDLA501 stereocomplex blends containing various $m b$ PDLAs at a $90 / 10$ blend ratio.

\begin{tabular}{|c|c|c|c|c|c|c|c|}
\hline \multirow[b]{2}{*}{ Blend component } & \multirow[b]{2}{*}{$\begin{array}{c}\mathbf{T}_{\mathbf{g}} \\
{\left[{ }^{\circ} \mathbf{C}\right]}\end{array}$} & \multirow[b]{2}{*}{$\begin{array}{c}\mathbf{T}_{\mathbf{c}} \\
{\left[{ }^{\circ} \mathbf{C}\right]}\end{array}$} & \multirow[b]{2}{*}{$\begin{array}{r}\Delta \mathbf{H}_{\mathbf{c}} \\
{[\mathrm{J} / \mathrm{g}]}\end{array}$} & \multicolumn{2}{|c|}{ Homo-crystallite } & \multicolumn{2}{|c|}{ Stereocomplex } \\
\hline & & & & $\begin{array}{c}\mathbf{T}_{\mathbf{m}} \\
{\left[{ }^{\circ} \mathbf{C}\right]}\end{array}$ & $\begin{array}{l}\Delta \Delta \mathbf{H}_{\mathbf{m}} \\
{[\mathrm{J} / \mathrm{g}]}\end{array}$ & $\begin{array}{c}\mathbf{T}_{\mathrm{m}} \\
{\left[{ }^{\circ} \mathbf{C}\right]}\end{array}$ & $\begin{array}{l}\Delta \mathbf{H}_{\mathbf{m}} \\
{[\mathbf{J} / \mathbf{g}]}\end{array}$ \\
\hline$l$-PLLA & 58 & 117 & 45.3 & 174 & 45.4 & - & - \\
\hline l-PLLA/mbPDLA051 & 55 & 113 & 35.3 & 174 & 39.4 & - & - \\
\hline$l$-PLLA $/ m b$ PDLA101 & 58 & 120 & 33.2 & 173 & 40.1 & - & - \\
\hline$l$-PLLA $/ m b$ PDLA201 & 59 & 120 & 36.2 & 172 & 34.6 & 186 & 6.6 \\
\hline$l$-PLLA $/ m b$ PDLA501 & 56 & 113 & 34.5 & 173 & 33.2 & 202 & 10.2 \\
\hline
\end{tabular}

mal properties of all blends are summarized in Table 3. The glass transition and homo-crystallite melting characteristics are clearly observed in all samples, which remain unchanged regardless of size of $m b$ PDLA components. Blends containing $m b$ PDLAs with $\bar{M}_{\mathrm{w}}$ higher than $60000 \mathrm{~g} / \mathrm{mol}$, i.e., $m b$ PDLA201 and $m b$ PDLA501, show an additional $T_{\mathrm{m}}$ of the stereocomplex structure at 186 and $210^{\circ} \mathrm{C}$, respectively. This indicates that a critical length of DLA sequences is required to form the stereocomplex structure, whose structural strength is dependent on the copolymer sizes.

Cold crystallization is observed in l-PLLA and all blends. The heat of cold crystallization $\left(\Delta H_{\mathrm{c}}\right)$ value of $l$-PLLA is similar to $\Delta H_{\mathrm{m}}$ of its homo-crystallite, indicating an absence of melt crystallization, i.e., the crystalline domains are mainly formed during the reheating process. The corresponding values for blends of small-sized $m b$ PDLAs are lower than $\Delta H_{\mathrm{m}}$, despite the absence of the stereocomplex melting peak. This reflects that the DLA short sequences act as nucleating species promoting the formation of homo-crystallite during melt crystallization [45, 46]. In contrast, $\Delta H_{\mathrm{c}}$ values of the blends containing large-sized $m b$ PDLAs, which show stereocomplex peak, are slightly higher than $\Delta H_{\mathrm{m}}$ of their homocrystallite. This is likely because stereocomplex formation occurs rapidly during the melt crystallization, but the crystallization is not complete at the applied cooling rate as the blends contain high l-PLLA content. When the sample is reheated higher than $T_{\mathrm{g}}$, chain rearrangements take place, resulting in the formation of homo-crystallites and additional stereocomplex structures.

In blends containing large-sized $m b$ PDLAs, $\Delta H_{\mathrm{m}}$ values of their stereocomplex endotherm increase with molecular weight of the $m b$ PDLA component, whereas the corresponding values of the homocrystallites significantly decrease. This is likely due to the suppression of homo-crystallization by the formation of the stronger stereocomplex structure. For blends consisting of small-sized $m b$ PDLAs, however, $\Delta H_{\mathrm{m}}$ remains constant as the suppression effect from the stereocomplex is negligible. All samples show a single $T_{\mathrm{g}}$ ranging from $55-59^{\circ} \mathrm{C}$, indicating miscible blends.

Effect of blend compositions on thermal properties of the stereocomplex blends is examined. DSC thermograms ( $2^{\text {nd }}$ heating scan $)$ of blends containing $m b$ PDLA501 at various blend ratios are compared in Figure 6. Cold crystallization is clearly observed in $l$-PLLA and $l$-PLLA-rich blends, along with the melting characteristic of homo-crystallite and stereocomplex. This reflects that the stereocomplex structure is formed at a much faster rate during the DSC cooling cycle, which retards formation of homo-crystallite in $l$-PLLA-rich blends [12]. In contrast, a 50:50 blend shows only the stereocomplex melting peak, with no cold crystallization, reflecting that no homo-crystallite domains are formed for an equimolar blend. Thermal properties of the blends are summarized in Table 4 . $T_{\mathrm{m}}$ of homo-crystallite shifts to lower temperatures, whereas that of the stereocomplex slightly shifts toward higher temperatures, with

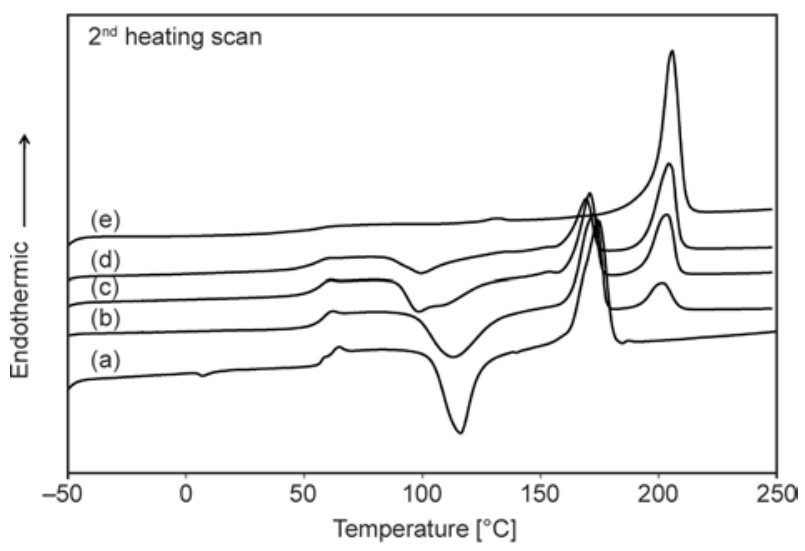

Figure 6. DSC thermograms ( $2^{\text {nd }}$ heating scan) of (a) $l$ PLLA, and $l$-PLLA $/ m b$-PDLA501 stereocomplex blends at various compositions: (b) $90 / 10$, (c) 80/ 20 , (d) $70 / 30$ and (e) $50 / 50$ 
Table 4. Thermal properties of $l$-PLLA/mbPDLA501 stereocomplex at various blend compositions

\begin{tabular}{|c|c|c|c|c|c|c|c|}
\hline \multirow{2}{*}{$\begin{array}{l}\text { Blend } \\
\text { ratios }\end{array}$} & \multirow[b]{2}{*}{$\begin{array}{c}\mathbf{T}_{\mathbf{g}} \\
{\left[^{\circ} \mathbf{C}\right]}\end{array}$} & \multirow[b]{2}{*}{$\begin{array}{c}\mathbf{T}_{\mathbf{c}} \\
{\left[{ }^{\circ} \mathbf{C}\right]}\end{array}$} & \multirow[b]{2}{*}{$\begin{array}{r}\Delta \mathbf{H}_{\mathbf{c}} \\
{[\mathbf{J} / \mathbf{g}]}\end{array}$} & \multicolumn{2}{|c|}{ Homo-crystallite } & \multicolumn{2}{|c|}{ Stereocomplex } \\
\hline & & & & $\begin{array}{c}\mathbf{T}_{\mathbf{m}} \\
{\left[{ }^{\circ} \mathbf{C}\right]}\end{array}$ & $\begin{array}{l}\Delta \mathbf{H}_{\mathbf{m}} \\
{[\mathrm{J} / \mathrm{g}]}\end{array}$ & $\begin{array}{c}\mathbf{T}_{\mathbf{m}} \\
{\left[{ }^{\circ} \mathbf{C}\right]}\end{array}$ & $\begin{array}{l}\Delta \mathbf{H}_{\mathbf{m}} \\
{[\mathbf{J} / \mathbf{g}]}\end{array}$ \\
\hline l-PLLA & 58 & 117 & 45.3 & 174 & 45.2 & - & - \\
\hline $90 / 10$ & 56 & 113 & 34.5 & 173 & 33.2 & 202 & 10.2 \\
\hline $80 / 20$ & 55 & 99 & 25.8 & 169 & 24.5 & 204 & 20.4 \\
\hline $70 / 30$ & 53 & 100 & 11.1 & 162 & 18.2 & 205 & 28.6 \\
\hline $50 / 50$ & 54 & - & - & - & - & 206 & 54.3 \\
\hline
\end{tabular}

an increase in the $m b$ PDLA501 contents. The heat of fusion $\left(\Delta H_{\mathrm{m}}\right)$ values also exhibit a similar trend, reflecting lower quality and contents of homo-crystallite, and vice versa for the stereocomplex. Single $T_{\mathrm{g}}$ is also observed in all blend samples, which decreases with an increase in the mbPDLA501 contents, reflecting a complete miscibility at all compositions. $\Delta H_{\mathrm{c}}$ values of $l$-PLLA-rich blends are similar to that of $\Delta H_{\mathrm{m}}$ values, also indicating that a cold crystallization mainly corresponds to homo-crystallite formation, whereas the stereocomplex is generated very fast during the melt crystallization.

\subsection{Mechanical properties of $l$ -}

\section{PLLA/mbPDLA stereocomplex blends}

Mechanical properties of the stereocomplex blends are evaluated in terms of tensile strength, modulus, and elongation at break, in which examples of stress-strain curves (4 replicates) of a l-PLLA/ $m b$ PDLA101 blend (90/10) are shown in Figure 7. Toughness is calculated from the area under the curves, which only represent the samples behaviors at low deformation rates, but not impact toughness. Table 5 summarizes mechanical properties of blends containing $m b$ PDLA101, as a function of the

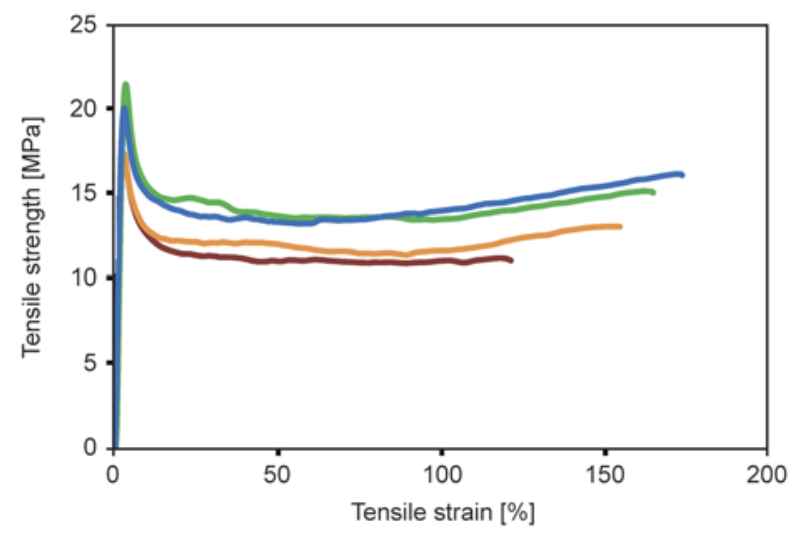

Figure 7. Stress-strain curves of $l$-PLLA $/ \mathrm{mbPDLA} 101$ stereocomplex blend at a 90/10 composition (4 replicates)
Table 5. Mechanical properties of $l$-PLLA/mbPDLA101 stereocomplex blends, as a function of blend ratios

\begin{tabular}{|c|c|c|c|c|}
\hline $\begin{array}{c}\text { Blend } \\
\text { ratios }\end{array}$ & $\begin{array}{c}\text { Tensile } \\
\text { strength } \\
{[\mathbf{M P a}]}\end{array}$ & $\begin{array}{c}\text { Young's } \\
\text { modulus } \\
{[\mathbf{M P a}]}\end{array}$ & $\begin{array}{c}\text { Elongation } \\
\text { at break } \\
{[\mathbf{\%}]}\end{array}$ & $\begin{array}{c}\text { Toughness } \\
{\left[\mathbf{m J} / \mathbf{m m}^{\mathbf{3}}\right]}\end{array}$ \\
\hline $100 / 0$ & $22.4 \pm 1.3$ & $1269 \pm 69$ & $13.8 \pm 2.1$ & $1.7 \pm 0.5$ \\
\hline $95 / 5$ & $17.2 \pm 1.6$ & $1065 \pm 131$ & $16.9 \pm 3.2$ & $1.7 \pm 0.6$ \\
\hline $90 / 10$ & $19.8 \pm 2.4$ & $1134 \pm 58$ & $144.9 \pm 29.1$ & $19.0 \pm 5.1$ \\
\hline $80 / 20$ & $18.2 \pm 2.1$ & $1004 \pm 99$ & $13.1 \pm 4.1$ & $1.4 \pm 0.6$ \\
\hline $70 / 30$ & $17.7 \pm 0.9$ & $964 \pm 41$ & $16.2 \pm 1.0$ & $1.9 \pm 0.4$ \\
\hline
\end{tabular}

Table 6. Mechanical properties of $l$-PLLA and $l$-PLLA/ $m b$ PDLA (90/10) stereocomplex blends consisting of different $m b$ PDLAs

\begin{tabular}{|l|c|c|c|c|}
\hline $\begin{array}{c}\text { Blend } \\
\text { component }\end{array}$ & $\begin{array}{c}\text { Tensile } \\
\text { strength } \\
{[\mathbf{M P a}]}\end{array}$ & $\begin{array}{c}\text { Young's } \\
\text { modulus } \\
{[\mathbf{M P a}]}\end{array}$ & $\begin{array}{c}\text { Elongation } \\
\text { at break } \\
{[\%]}\end{array}$ & $\begin{array}{c}\text { Toughness } \\
{\left[\mathbf{m J} / \mathbf{m m}^{\mathbf{3}}\right]}\end{array}$ \\
\hline$l$-PLLA & $22.4 \pm 1.3$ & $1269 \pm 69$ & $13.8 \pm 2.1$ & $1.7 \pm 0.5$ \\
\hline$m b$ PDLA051 & $16.9 \pm 1.0$ & $998 \pm 83$ & $63.4 \pm 22.1$ & $8.6 \pm 2.9$ \\
\hline$m b$ PDLA101 & $19.8 \pm 2.4$ & $1134 \pm 58$ & $144.9 \pm 29.1$ & $19.0 \pm 5.1$ \\
\hline$m b$ PDLA201 & $32.1 \pm 2.2$ & $1120 \pm 62$ & $76.3 \pm 17.0$ & $13.3 \pm 2.8$ \\
\hline$m b$ PDLA501 & $30.3 \pm 0.9$ & $1631 \pm 189$ & $97.7 \pm 28.4$ & $26.1 \pm 7.7$ \\
\hline
\end{tabular}

blend contents. Slight decreases in all properties are observed with an inclusion of $m b$ PDLA101, except those of the $90 / 10$ blend, whose elongation at break and toughness are largely increased without sacrificing much of the tensile strength and modulus. This reflects a strong influence of an optimum blend ratio on the improvement of the blends mechanical properties.

Enhancements in tensile strength and modulus of the blends are also feasible by varying $m b$ PDLAs sizes. Table 6 summarizes mechanical properties of stereocomplex blends of different $m b$ PDLAs, prepared at the same composition (90/10). The blend consisting of $m b$ PDLA501 exhibits higher tensile strength and modulus than those of $l$-PLLA, whereas those of smaller $m b$ PDLAs show slight drops in the values. This reflects that a critical molecular weight value of $m b$ PDLA is required in the formation of appropriate stereocomplex structure, which in turns imposes a large influence on the enhancement of their mechanical properties.

\subsection{Rheological properties of l-PLLA/mbPDLA stereocomplex blends}

Rheology behaviors of stereocomplex blends containing different $m b$ PDLAs, prepared at a 90/10 ratio, are examined at a fixed strain of $5 \%$. Figure 8 shows results on complex viscosity $\left(\eta^{*}\right)$, storage modulus $\left(G^{\prime}\right)$, loss modulus $\left(G^{\prime \prime}\right)$, and $\tan \delta$ of the 

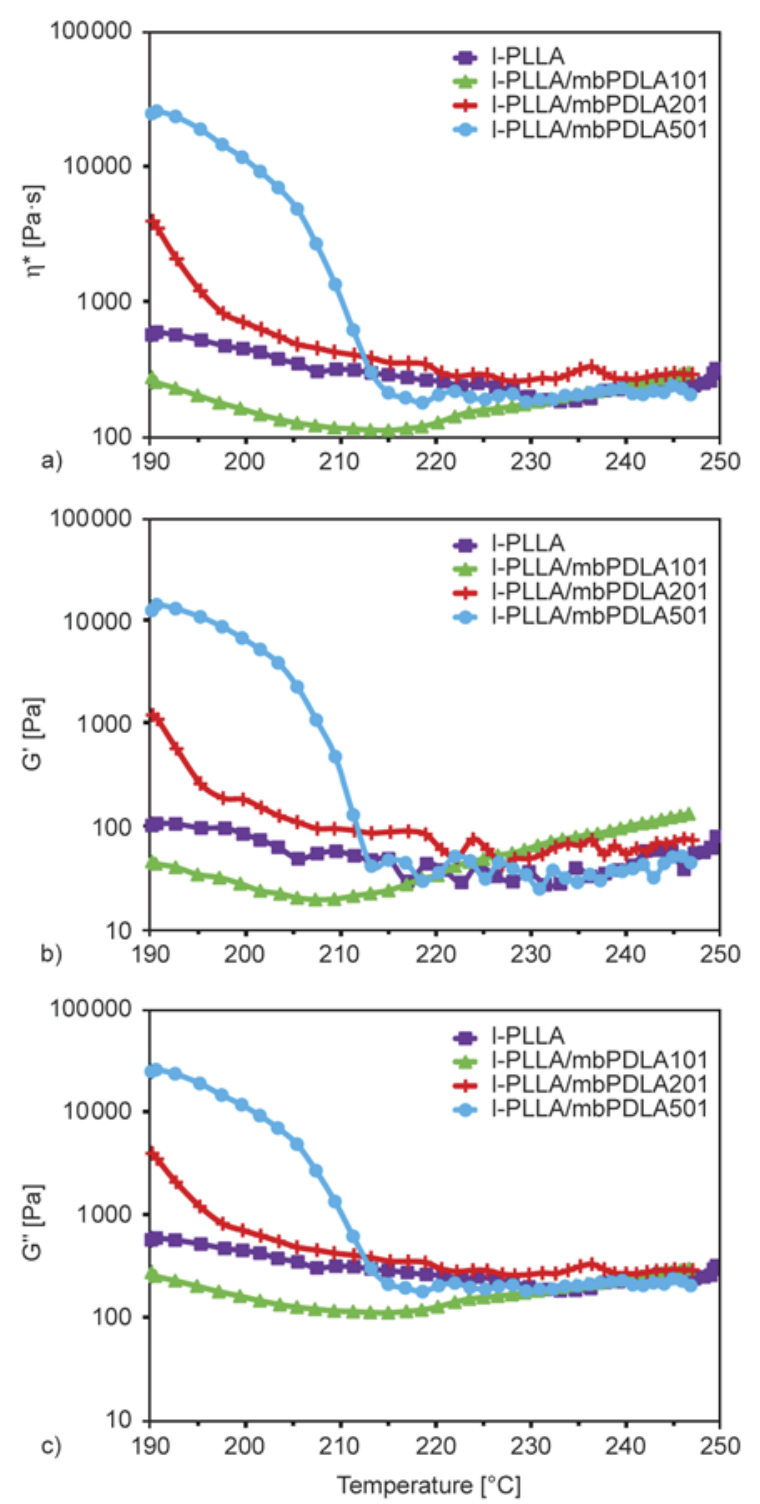

Figure 8. Temperature dependence of complex viscosity $\left(\eta^{*}\right)\left(\right.$ a), storage moduli $\left(G^{\prime}\right)(\mathrm{b})$ and loss moduli $\left(G^{\prime \prime}\right)(\mathrm{c})$ of stereocomplex blends containing different $m b$ PDLAs

blends, as a function of temperature. At temperatures below their stereocomplex's $T_{\mathrm{m}}$, the blends consisting of $m b$ PDLA501 and $m b$ PDLA201 show high $\eta^{*}, G^{\prime}$ and $G^{\prime \prime}$ values, due to the presence of the stereocomplex structure in a glassy state. An incorporation of small-sized $m b$ PDLA101 leads to a reduction in the values, compared to $l$-PLLA, as this acts as a plasticizer. When the chain length of $m b$ PDLAs increases, the value sharply increases, where an increase of 1 and 2 orders of magnitude is observed in $m b$ PDLA201 and $m b$ PDLA501, respectively. This reflects a formation of stronger interaction, i.e., hydrogen bonding, between the 2 stereoconstituents $[2,47,48]$. A sharp decrease in the values is observed when the structure melts. This

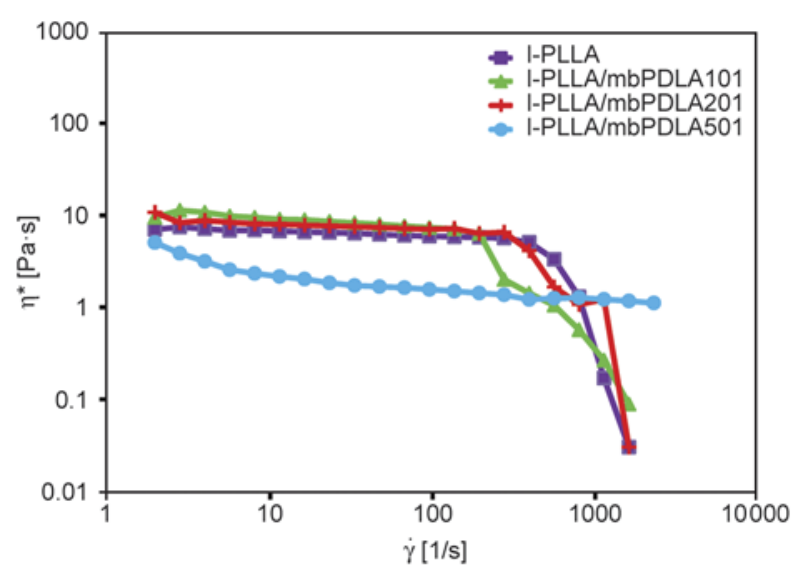

Figure 9. Steady shear viscosity of stereocomplex blends containing different $m b$ PDLAs at a 90:10 blend composition

behavior is not seen in blends consisting of smaller $m b$ PDLAs, due to the absence (or low content) of stereocomplex structure, as previously discussed.

The steady shear rheology behaviors, as a function of shear rate, of blends containing different $m b$ PDLAs (90/10 blend compositions) are shown in Figure 9. The experiments are conducted at $230^{\circ} \mathrm{C}$, above $T_{\mathrm{m}}$ of the stereocomplex. Typical non-Newtonian behavior is observed in all samples. At low shear rates, the shear viscosity of stereocomplex blends are comparable to that of $l$-PLLA, except that of $m b$ PDLA501, which is about 1 order of magnitude lower. This is due to the influence of its branched component, which possesses the required arm length. At higher shear rates $(>2001 / \mathrm{s})$, the shear thinning behavior is clearly evidenced, except for that of $m b$ PDLA501. The results also indicate that this behavior of the blends is observed earlier (at lower shear rates) than that of $l$-PLLA, in which the inclusion of $m b$ PDLAs with shorter arm lengths shows a sudden drop in the viscosity at lower rates. Interestingly, the stereocomplex blend of mbPDLA501 does not exhibit shear-thinning characteristics in this shear rate range $(<10,0001 / \mathrm{s})$, probably because of its sufficiently-long arm lengths that enable effective chain entanglements, and its strong interaction between the 2 enantiomeric structures. Given its excellent mechanical property, the l-PLLA/ $m b$ PDLA501 blend show high potential for industrial use, as this rheological property also leads to easy processing conditions.

\section{Conclusions}

Multi-branched PDLAs ( $m b$ PDLAs) derived from polyglycidol (PG) core are successfully used to 
enhance mechanical properties and processing conditions of commercial linear-structured PLLA ( $l$-PLLA). Chemical structures of $m b$ PDLAs are controlled by adjusting the feed ratio of DLA monomer to the PG macro-initiator, which in turns leads to a variation in the copolymers thermal and physical properties. The mbPDLAs structures and blend compositions impose strong effects on physical and mechanical properties, i.e., $T_{\mathrm{g}}, T_{\mathrm{m}}$, toughness, tensile strength, modulus, and elongation at break, of the $l$-PLLA $/ \mathrm{m} b$ PDLAs stereocomplex blends. The stereocomplex with a blend ratio of 90/10 exhibits the most desirable properties, in which the highest elongation at break value is gained whereas tensile strength and moduli are comparable to $l$-PLLA. The material also exhibits the lowest complex viscosity, which provides easy processing conditions. This is achieved by the incorporation of copolymers with multi-branched structures and an ability to form a much stronger stereocomplex structure.

\section{Acknowledgements}

This research is partially supported by a grant of the National Metal and Materials Technology Center, and the National Research Council of Thailand (NRCT). The authors thank PURAC (Netherlands) for the supply of PLLA and DLA samples. W.S. is grateful for a scholarship from the Center of Excellence in Material Science, Construction, and Maintenance Technology, Thammasat University.

\section{References}

[1] Dorgan J. R., Lehermeier H., Mang M.: Thermal and rheological properties of commercial-grade poly(lactic acid)s. Journal of Polymers and the Environment, 8, 1-9 (2000).

DOI: 10.1023/A:1010185910301

[2] Fukushima K., Kimura Y.: Stereocomplexed polylactides (Neo-PLA) as high-performance bio-based polymers: Their formation, properties, and application. Polymer International, 55, 626-642 (2006). DOI: $10.1002 /$ pi.2010

[3] Opaprakasit M., Petchsuk A., Opaprakasit P., Chongprakobkit S.: Effects of synthesis conditions on chemical structures and physical properties of copolyesters from lactic acid, ethylene glycol and dimethyl terephthalate. Express Polymer Letters, 3, 458-468 (2009). DOI: $10.3144 /$ expresspolymlett.2009.56
[4] Namkajorn M., Petchsuk A., Opaprakasit M., Opaprakasit P.: Synthesis and characterizations of degradable aliphatic-aromatic copolyesters from lactic acid, dimethyl terephthalate and diol: Effects of diol type and monomer feed ratio. Express Polymer Letters, 4, 415422 (2010).

DOI: $10.3144 /$ expresspolymlett.2010.52

[5] Opaprakasit M., Kongtong W., Petchsuk A., Opaprakasit P.: Processability enhancement of poly(lactic acidco-ethylene terephthalate) by blending with poly(ethylene-co-vinyl acetate), poly(3-hydroxybutyrate-co-3hydroxyvalerate), and poly(butylene succinate). Polymer Bulletin, 67, 275-290 (2011).

DOI: $10.1007 / \mathrm{s} 00289-010-0421-8$

[6] Nguyen T-H., Tangboriboonrat P., Rattanasom N., Petchsuk A., Opaprakasit M., Thammawong C., Opaprakasit P.: Polylactic acid/ethylene glycol triblock copolymer as novel crosslinker for epoxidized natural rubber. Journal of Applied Polymer Science, 124, 164174 (2012).

DOI: 10.1002/app.35088

[7] Petchsuk A., Submark W., Opaprakasit P.: Development of crosslinkable poly(lactic acid-co-glycidyl methacrylate) copolymers and their curing behaviors. Polymer Journal, 45, 406-412 (2013).

DOI: $10.1038 / \mathrm{pj} .2012 .159$

[8] Lasprilla A. J. R., Martinez G. A. R., Lunelli B. H., Jardini A. L., Filho R. M.: Poly-lactic acid synthesis for application in biomedical devices - A review. Biotechnology Advances, 30, 321-328 (2012).

DOI: $10.1016 /$ j.biotechadv.2011.06.019

[9] Liu H., Zhang J.: Research progress in toughening modification of poly(lactic acid). Journal of Polymer Science Part B: Polymer Physics, 49, 1051-1083 (2011). DOI: $10.1002 /$ polb.22283

[10] Tsuji H.: Poly(lactide) stereocomplexes: Formation, structure, properties, degradation, and applications. Macromolecular Bioscience, 5, 569-597 (2005). DOI: $10.1002 / \mathrm{mabi} .200500062$

[11] Zhou H., Lawrence J. G., Bhaduri S. B.: Fabrication aspects of PLA-CaP/PLGA-CaP composites for orthopedic applications: A review. Acta Biomaterialia, 8, 1999-2016 (2012). DOI: $10.1016 /$ j.actbio.2012.01.031

[12] Opaprakasit P., Opaprakasit M.: Thermal properties and crystallization behaviors of polylactide and its enantiomeric blends. Macromolecular Symposia, 264, 113-120 (2008).

DOI: $10.1002 / \mathrm{masy} .200850418$

[13] Avérous L.: Biodegradable multiphase systems based on plasticized starch: A review. Journal of Macromolecular Science Part C: Polymer Reviews, 44, 231-274 (2004).

DOI: $\underline{10.1081 / M C-200029326}$ 
[14] Datta R., Henry M.: Lactic acid: Recent advances in products, processes and technologies $-\mathrm{A}$ review. Journal of Chemical Technology and Biotechnology, 81, 1119-1129 (2006). DOI: $10.1002 /$ jctb. 1486

[15] Lee S., Lee J. W.: Characterization and processing of biodegradable polymer blends of poly(lactic acid) with poly(butylene succinate adipate). Korea Australia Rheology Journal, 17, 71-77 (2005).

[16] Ikada Y., Jamshidi K., Tsuji H., Hyon S. H.: Stereocomplex formation between enantiomeric poly(lactides). Macromolecules, 20, 904-906 (1987).

DOI: $10.1021 / \mathrm{ma} 00170 \mathrm{a} 034$

[17] Tsuji H., Ikada Y.: Stereocomplex formation between enantiomeric poly(lactic acid)s. XI. Mechanical properties and morphology of solution-cast films. Polymer, 40, 6699-6708 (1999).

DOI: 10.1016/S0032-3861(99)00004-X

[18] Purnama P., Kim S. H.: Stereocomplex formation of high-molecular-weight polylactide using supercritical fluid. Macromolecules, 43, 1137-1142 (2010). DOI: $10.1021 / \mathrm{ma902536p}$

[19] Purnama P., Kim S. H.: Stereocomplex formation of polylactide using microwave irradiation. Polymer International, 63, 741-745 (2014).

DOI: $10.1002 /$ pi.4581

[20] Arikawa Y., Serizawa T., Mukose T., Kimura Y., Akashi M.: Characterization of poly(lactide)s nanotubes consist of poly(lactide)s stereocomplex hollow particles. in ' $55^{\text {th }}$ Society of Polymer Science Japan Symposium on Macromolecules' Toyama, Japan, vol 55, 4040-4046 (2006).

[21] Kim S. H., Tan J. P. K., Nederberg F., Fukushima K., Yang Y. Y., Waymouth R. M., Hedrick J. L.: Mixed micelle formation through stereocomplexation between enantiomeric poly(lactide) block copolymers. Macromolecules, 42, 25-29 (2009).

DOI: $10.1021 / \mathrm{ma} 801739 \mathrm{x}$

[22] Kondo K., Kida T., Ogawa Y., Arikawa Y., Akashi M.: Nanotube formation through the continuous one-dimensional fusion of hollow nanocapsules composed of layer-by-layer poly(lactic acid) stereocomplex films. Journal of the American Chemical Society, 132, 82368237 (2010). DOI: $10.1021 /$ ja1020537

[23] Brizzolara D., Cantow H-J., Diederichs K., Keller E., Domb A. J.: Mechanism of the stereocomplex formation between enantiomeric poly(lactide)s. Macromolecules, 29, 191-197 (1996).

DOI: $10.1021 / \mathrm{ma} 951144 \mathrm{e}$

[24] Fukushima K., Chang Y-H., Kimura Y.: Enhanced stereocomplex formation of poly(L-lactic acid) and poly (D-lactic acid) in the presence of stereoblock poly(lactic acid). Macromolecular Bioscience, 7, 829-835 (2007).

DOI: $10.1002 / m a b i .200700028$
[25] Takasaki M., Ito H., Kikutani T.: Development of stereocomplex crystal of polylactide in high-speed melt spinning and subsequent drawing and annealing processes. Journal of Macromolecular Science Part B: Physics, 42 B, 403-420 (2003).

DOI: $10.1081 / \mathrm{MB}-120021570$

[26] Zhang J., Sato H., Tsuji H., Noda I., Ozaki Y.: Infrared spectroscopic study of $\mathrm{CH}_{3} \cdots \mathrm{O}=\mathrm{C}$ Interaction during poly(L-lactide)/poly(D-lactide) stereocomplex formation. Macromolecules, 38, 1822-1828 (2005).

DOI: $10.1021 / \mathrm{ma} 047872 \mathrm{~W}$

[27] Zhang J., Tashiro K., Tsuji H., Domb A. J.: Investigation of phase transitional behavior of poly(L-lactide)/ poly(D-lactide) blend used to prepare the highly-oriented stereocomplex. Macromolecules, 40, 1049-1054 (2007). DOI: $10.1021 / \mathrm{ma} 061693 \mathrm{~s}$

[28] Fukushima K., Hirata M., Kimura Y.: Synthesis and characterization of stereoblock poly(lactic acid)s with nonequivalent $\mathrm{D} / \mathrm{L}$ sequence ratios. Macromolecules, 40, 3049-3055 (2007). DOI: $10.1021 / \mathrm{ma} 070156 \mathrm{k}$

[29] Fukushima K., Kimura Y.: A novel synthetic approach to stereo-block poly(lactic acid). Macromolecular Symposia, 224, 133-143 (2005).

DOI: $10.1002 /$ masy.200550612

[30] Yui N., Dijkstra P. J., Feijen J.: Stereo block copolymers of L- and D-lactides. Die Makromolekulare Chemie, 191, 481-488 (1990).

DOI: $10.1002 / \mathrm{macp} .1990 .021910303$

[31] Hirata M., Kimura Y.: Thermomechanical properties of stereoblock poly(lactic acid)s with different PLLA/ PDLA block compositions. Polymer, 49, 2656-2661 (2008).

DOI: $10.1016 /$ j.polymer.2008.04.014

[32] Quynh T. M., Mitomo H., Yoneyama M., Hien N. Q.: Properties of radiation-induced crosslinking stereocomplexes derived from poly(L-lactide) and different poly(D-lactide). Polymer Engineering and Science, 49, 970-976 (2009).

DOI: $10.1002 /$ pen.21309

[33] Seiler M.: Hyperbranched polymers: Phase behavior and new applications in the field of chemical engineering. Fluid Phase Equilibria, 241, 155-174 (2006). DOI: 10.1016/j.fluid.2005.12.042

[34] Liu J., Lou L., Yu W., Liao R., Li R., Zhou C.: Long chain branching polylactide: Structures and properties. Polymer, 51, 5186-5197 (2010). DOI: 10.1016/j.polymer.2010.09.002

[35] Numata K., Srivastava R. K., Finne-Wistrand A., Albertsson A-C., Doi Y., Abe H.: Branched poly(lactide) synthesized by enzymatic polymerization: Effects of molecular branches and stereochemistry on enzymatic degradation and alkaline hydrolysis. Biomacromolecules, 8, 3115-3125 (2007).

DOI: $10.1021 / \mathrm{bm} 700537 \mathrm{x}$ 
[36] Shao J., Sun J., Bian X., Cui Y., Li G., Chen X.: Investigation of poly(lactide) stereocomplexes: 3-armed poly(L-lactide) blended with linear and 3-armed enantiomers. Journal of Physical Chemistry B, 116, $9983-$ 9991 (2012).

DOI: $10.1021 / j p 303402 \mathrm{j}$

[37] Andersson S. R., Hakkarainen M., Inkinen S., Södergård A., Albertsson A-C.: Customizing the hydrolytic degradation rate of stereocomplex PLA through different PDLA architectures. Biomacromolecules, 13, 1212 1222 (2012).

DOI: $10.1021 / \mathrm{bm} 300196 \mathrm{~h}$

[38] Inkinen S., Stolt M., Södergård A.: Effect of blending ratio and oligomer structure on the thermal transitions of stereocomplexes consisting of a D-lactic acid oligomer and poly(L-lactide). Polymers for Advanced Technologies, 22, 1658-1664 (2011).

DOI: $10.1002 /$ pat. 1654

[39] Gottschalk C., Wolf F., Frey H.: Multi-arm star poly(Llactide) with hyperbranched polyglycerol core. Macromolecular Chemistry and Physics, 208, 1657-1665 (2007).

DOI: $10.1002 /$ macp. 200700168

[40] Ouchi T., Ichimura S., Ohya Y.: Synthesis of branched poly(lactide) using polyglycidol and thermal, mechanical properties of its solution-cast film. Polymer, 47, 429-434 (2006).

DOI: $10.1016 /$ j.polymer.2005.11.039

[41] Kainthan R. K., Muliawan E. B., Hatzikiriakos S. G., Brooks D. E.: Synthesis, characterization, and viscoelastic properties of high molecular weight hyperbranched polyglycerols. Macromolecules, 39, 7708 7717 (2006).

DOI: $10.1021 / \mathrm{ma} 0613483$

[42] Sunder A., Hanselmann R., Frey H., Mülhaupt R.: Controlled synthesis of hyperbranched polyglycerols by ring-opening multibranching polymerization. Macromolecules, 32, 4240-4246 (1999).

DOI: $10.1021 / \mathrm{ma} 990090 \mathrm{w}$
[43] Tokar R., Kubisa P., Penczek S., Dworak A.: Cationic polymerization of glycidol: Coexistence of the activated monomer and active chain end mechanism. Macromolecules, 27, 320-322 (1994). DOI: $10.1021 / \mathrm{ma} 00080 \mathrm{a} 002$

[44] Vandenberg E. J.: Polymerization of glycidol and its derivatives: A new rearrangement polymerization. Journal of Polymer Science: Polymer Chemistry Edition, 23, 915-949 (1985).

DOI: $10.1002 /$ pol.1985.170230401

[45] Schmidt S. C., Hillmyer M. A.: Polylactide stereocomplex crystallites as nucleating agents for isotactic polylactide. Journal of Polymer Science Part B: Polymer Physics, 39, 300-313 (2001).

DOI: $10.1002 / 1099-0488(20010201) 39: 3<300:: A I D-$

$$
\text { POLB1002>3.0.CO;2-M }
$$

[46] Tsuji H., Takai H., Saha S. K.: Isothermal and nonisothermal crystallization behavior of poly(L-lactic acid): Effects of stereocomplex as nucleating agent. Polymer, 47, 3826-3837 (2006).

DOI: 10.1016/j.polymer.2006.03.074

[47] Opaprakasit P., Opaprakasit M., Tangboriboonrat P.: Crystallization of polylactide and its stereocomplex investigated by two-dimensional Fourier transform infrared correlation spectroscopy employing carbonyl overtones. Applied Spectroscopy, 61, 1352-1358 (2007). DOI: $10.1366 / 000370207783292235$

[48] Zhang J., Sato H., Tsuji H., Noda I., Ozaki Y.: Differences in the $\mathrm{CH}_{3} \cdots \mathrm{O}=\mathrm{C}$ interactions among poly(Llactide), poly(L-lactide)/poly(D-lactide) stereocomplex, and poly(3-hydroxybutyrate) studied by infrared spectroscopy. Journal of Molecular Structure, 735736, 249-257 (2005).

DOI: $10.1016 /$ j.molstruc.2004.11.033 